\title{
Effects of species richness, identity and environmental variables on growth in planted mangroves in Kenya
}

\author{
Bernard Y. K. Kirui ${ }^{1, *}$, James G. Kairo1 ${ }^{1}$, Martin W. Skov ${ }^{2}$, Maurizio Mencuccini ${ }^{3}$, \\ Mark Huxham ${ }^{4}$ \\ ${ }^{1}$ Kenya Marine and Fisheries Research Institute, PO Box 81651, Mombasa, Kenya \\ ${ }^{2}$ School of Ocean Sciences, Bangor University, Menai Bridge, Anglesey LL59 5AB, Bangor, UK \\ ${ }^{3}$ School of Geosciences, University of Edinburgh, Edinburgh EH9 3JN, UK \\ ${ }^{4}$ School of Life, Sport and Social Sciences, Edinburgh Napier University, Edinburgh EH10 5DT, UK
}

\begin{abstract}
Anthropogenic impacts on biodiversity across a wide range of ecosystems are well documented; however the responses of ecosystems to reduced diversity are still poorly understood. We investigated the effects of species richness, species identity and environmental variables on aboveground biomass increment using replanted mangroves at Gazi Bay, Kenya. We planted 32 plots $\left(36 \mathrm{~m}^{2}\right)$ with 8 treatments: all possible combinations of the trees Avicennia marina, Bruguiera gymnorrhiza, and Ceriops tagal and an unplanted control. Trees were planted in July and August 2004 and monitored annually until 2009. Growth was slow in the first $2 \mathrm{yr}$ of the study, but by 2007 there was a significant treatment effect on aboveground biomass. A. marina showed strong competitive traits, with the best growth overall and enhanced growth of individual trees when planted in mixed species plots. The highest biomass was recorded in 3-species mixes; partitioning the net effects of species mixing showed a strong species selection effect, but there was also a complementarity effect in some of the three species plots. Biomass was positively correlated with presence of $A$. marina and negatively correlated with sediment salinity. We conclude that there is variation in the stages of plant development at which species richness effects manifest themselves; in addition the effects of environmental variables have a bearing on the nature and direction of the relationship between species richness and ecosystem function.
\end{abstract}

KEY WORDS: Biomass - Facilitation - Kenya · Mangrove reforestation $\cdot$ Saplings $\cdot$ Species richness $\cdot$ Ecosystem function written consent of the publisher

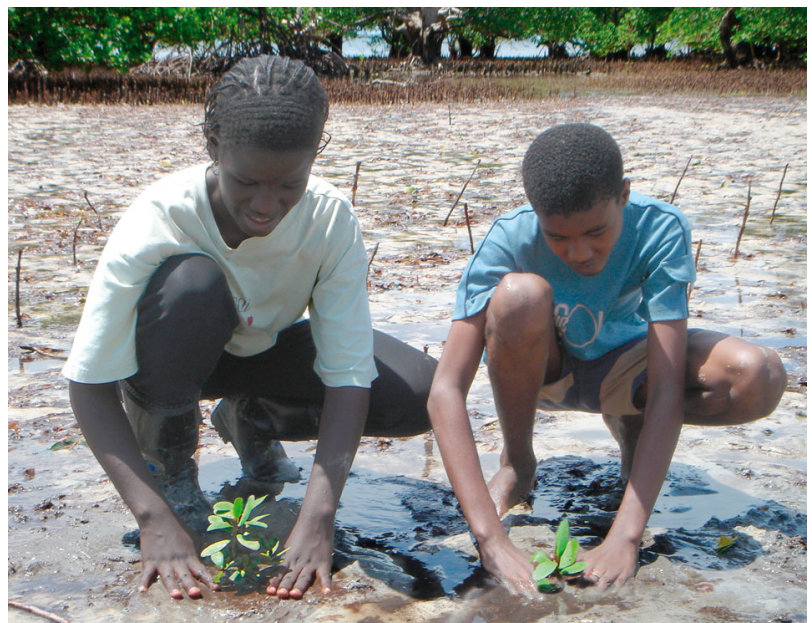

Restoration of biodiversity in degraded coastal sites in Gazi Bay, Kenya, is driven by mangrove species that easily adapt to the prevailing environmental conditions.

Photo: Martin Skov

\section{INTRODUCTION}

The growing awareness of human domination of Earth's ecosystems, and the resulting reduction in species diversity in many habitats worldwide (Kareiva et al. 2007), has stimulated interest among ecologists in understanding the relationship between biodiversity and ecosystem function (see reviews by Hector \& Hooper 2002, Schmid 2002, Hooper et al. 2005, Spehn et al. 2005, Cardinale et al. 2011). Restoration of ecosystems ultimately depends on this 
understanding. Numerous attempts have been made to investigate relationships between biodiversity and ecosystem functions experimentally and by using comparative approaches; to date, the most compelling evidence for strong linkages has come from experiments in grassland ecosystems in which species diversity was manipulated directly in replicated treatments (Hector et al. 1999, Fornara \& Tilman 2009, Isbell \& Wilsey 2011, Reich et al. 2012).

Earlier work was criticized for failing to account for the influence of the 'selection effect', that is, the higher probability of including 1 or a few highly productive species in the most species-rich treatments (Loreau \& Hector 2001, Fargione et al. 2007). In addition, studies that use only a small fraction of the relevant species pool at a given site may not produce results that are applicable under natural conditions. Although grasslands still predominate in the literature, there are increasing numbers of studies from other ecosystems including a few from marine habitats (Emmerson \& Huxham 2002, Bruno et al. 2005, Cardinale et al. 2007). However, the ecological significance of diversity remains unknown in many systems. For example, it is uncertain what relevance studies on short-lived non-woody plants have to woody ecosystems such as forests. Long-term manipulative experiments using trees have recently been initiated at a number of sites across Europe, and early findings suggest a positive influence of species diversity on a range of ecosystem functions (Oelmann et al. 2010, Zeugin et al. 2010, Hector et al. 2011) but are unlikely to yield conclusive results rapidly.

Mangroves are trees found in estuaries and intertidal zones in tropical and subtropical regions (Tomlinson 1986). Whilst the mangrove ecosystem supports a relatively low diversity of plant forms, it is rich in other organisms, including arthropods, molluscs, fishes and birds (Field et al. 1998). A relationship between biodiversity and ecosystem functions has been inferred (MacNae 1968, Field et al. 1998), but rarely tested directly in mangrove ecosystems. Previous studies that have used comparative approaches (Bosire et al. 2003, Kirui et al. 2006, Mukhopadhyay et al. 2006, Kairo et al. 2008) have focused on the influence of management systems and environmental contexts on ecological functions; they have generally emphasized the roles of nutrient fluxes and macrofauna in determining the net primary productivity of the single dominant mangrove species, such as Bruguiera gymnorrhiza (L.) Lamk. 1797-8. Whilst comparative methods can provide useful information on the main drivers of ecosystem function, they usually cannot explain the underlying mechanisms behind relationships (Huston 1997), and can obscure within-habitat variations (Schmid 2002). Mangrove forests are naturally comprised of a small number of mangrove species, which means that the manipulation of most of the species present is feasible, and they can grow relatively fast (Kairo 1995, Bosire et al. 2008, Kairo et al. 2008); hence experimental approaches to biodiversity and ecosystem linkages are possible. To our knowledge, however, no previous experiment has been conducted in a mangrove ecosystem where species diversity was manipulated.

In July 2004, a long-term experiment, measuring a range of ecosystem functions, was initiated in Kenya. The experiment used 3 species (Avicennia marina [Forssk.] Vierh, 1753, Bruguiera gymnorrhiza and Ceriops tagal [Perr.] C.B. Robinson 1908) that grow sympatrically near the experimental site to create diversity treatments containing all possible species combinations. Not only are plantation studies needed to understand how mangrove conservation and management stakeholders in Kenya may proceed with reforestation programmes for such sites, but also, species trials present an optimal context for testing the effect of diversity on ecosystem services. Here we present findings on the effects of species diversity and soil conditions on one of these ecosystem functions, i.e. aboveground biomass production. The null hypotheses were:

(1) Species diversity and identity of mangroves has no effect on the aboveground productivity of planted plots.

(2) Aboveground productivity is not influenced by variations in environmental factors over the range typical of the local soft shore intertidal environment.

The study was therefore designed to contribute towards improvements in mangrove restoration as well as to provide an insight from a coastal ecosystem on the biodiversity- ecosystem function debate.

\section{MATERIALS AND METHODS}

\section{Site description}

The study was conducted at Gazi Bay $\left(4^{\circ} 28^{\prime} \mathrm{S}\right.$, $\left.39^{\circ} 29^{\prime} \mathrm{E}\right)$, located on the southern coast of Kenya $\sim 55 \mathrm{~km}$ from Mombasa (Fig. 1). It is a shallow coastal ecosystem with extensive mangrove formations intersected by 2 creeks. The total area of the bay excluding the area covered by mangroves is $10 \mathrm{~km}^{2}$. Two seasonal rivers (Kidogoweni and Mkurumudji) drain into the bay, and there is restricted groundwater seepage (Tack \& Polk 1999). 


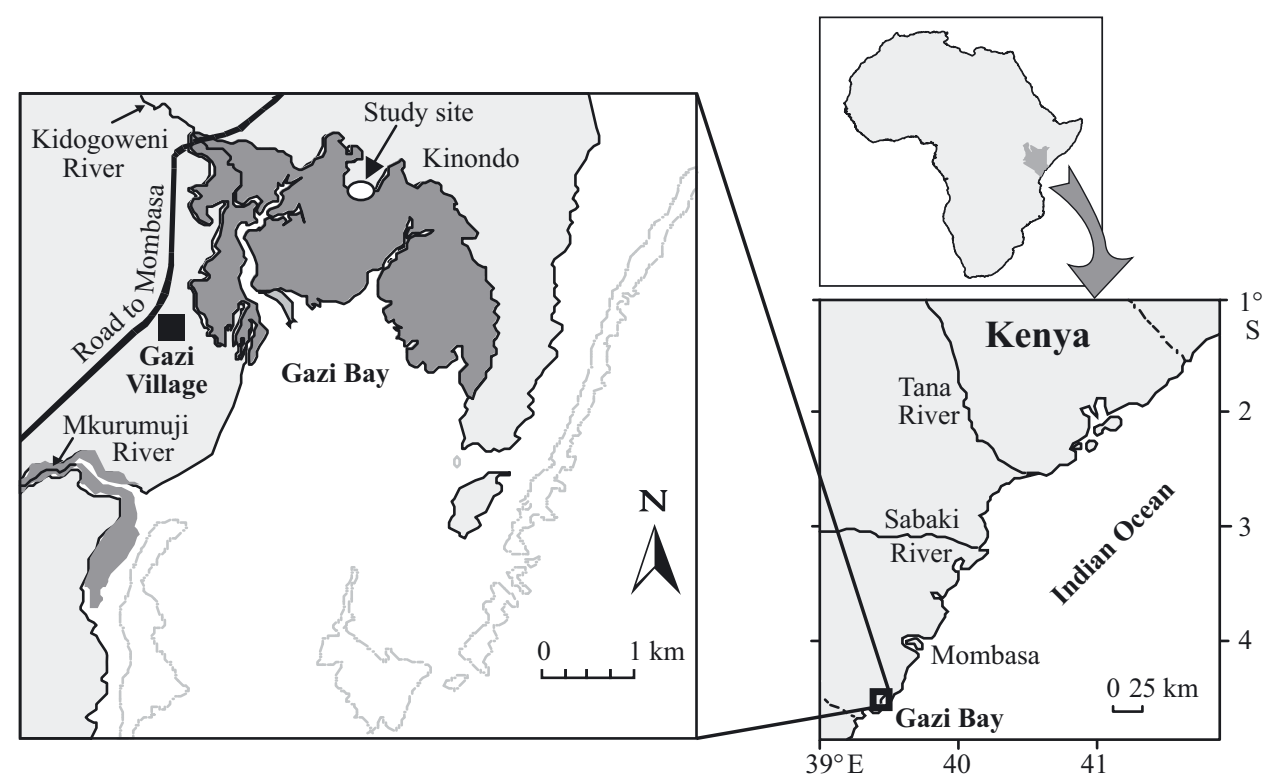

Fig. 1. Study area (modified from Bosire et al. 2003). Dark grey: mangrove cover; light grey lines: reefs

Seasonal rains dominate the local climate with 2 rainy seasons: heavy rains in April to June and lighter short rains in October to November. The total annual rainfall ranges between 1000 and $1600 \mathrm{~mm}$.

Mangroves in Gazi have been exploited for many years, mainly as sources of fuelwood and building poles for the local community as well as to provide wood for brick- and chalk- making industries in the 1970s (Kairo 1995). Clear-felling left some areas of the bay completely denuded (Bosire et al. 2003), and these sites still show few signs of natural regeneration. One of these cleared sites was used for the present study (Fig. 1); it is a high tidal site in inundation class IV of Watson (1928), i.e. flooded only at spring high tides. The topsoil at the site is sandy while the subsoil is peaty sand.

The 3 species used in this experiment grow sympatrically in the remaining natural forest contiguous to the experimental site (in particular in transitional areas between zones) and were present on the site before clear-felling. Kenya has 9 mangrove species; highly elevated shore locations such as the study site commonly have 1 to 4 species.

\section{Experimental design}

The effects of mangrove species identity and richness, as well as of environmental variables, on aboveground biomass were investigated in a planted area of $2800 \mathrm{~m}^{2}$. Three species of mangrove-Avicennia marina, Bruguiera gymnorrhiza and Ceriops tagal-were used in the experiment. The 8 treat- ments consisted of each species on its own, all possible 2-species mixes, the 3-species mix and unplanted control plots. In 2- and 3-species plots, saplings were planted in alternate patterns in a regular matrix along the lines. Plots were $6 \times 6 \mathrm{~m}$, with a planting distance of $0.6 \mathrm{~m}$ between trees; hence each planted plot consisted of 121 trees (or 33611 trees ha ${ }^{-1}$ ), giving 3388 trees in total. Inter-plot distances were kept to a minimum of $6 \mathrm{~m}$; this is greater than the home range size of fiddler crabs (Uca spp.), the dominant epifauna at the site, hence helping to ensure independence of plots (Skov \& Hartnoll 2002). Treatments were randomly allocated to plots in a replicated random block design, with 2 blocks (separated by $\sim 100 \mathrm{~m}$ ), each block containing 2 replicates; thus there were 4 replicate plots for each treatment and a total of 32 plots. Seeds and other propagules of the 3 species were collected from the surrounding forest in early 2004 and grown in nursery plots located in an adjacent intertidal site using local soil with no artificial fertilizer application. Seedlings were 'hardened' for a period of $1 \mathrm{mo}$ and were subsequently planted in the treatment plots in the months of July/August 2004 when the region experiences short rains. All planted saplings were $\sim 30 \mathrm{~cm}$ in height, of the same age, and were randomly allocated to relevant plots.

\section{Environmental factors}

The following environmental variables were measured in all plots before planting: (1) redox potential, (2) pore water salinity, (3) sediment organic carbon 
content, (4) sediment grain size, (5) sediment temperature, (6) nutrient content and (7) height above chart datum. Areas $<1.0 \mathrm{~m}$ from plot edges were not sampled to avoid 'edge effects'. For variables 1 to 6 , the results for each plot were means of 4 random subsamples; height above sea level was measured in the centre of each plot using a levelling theodolite. Sediment cores for redox and salinity measurements were extracted using a $50 \mathrm{~cm}$ long, $40 \mathrm{~mm}$ diameter locally modified D-section soil corer. A portable redox meter was used to take redox measurements in the extracted core at 10 and $40 \mathrm{~cm}_{i} \sim 50 \mathrm{~g}$ sediment per depth were then removed, bagged and the pore water salinity measured in the laboratory after centrifuging, using a hand-held refractometer. Surface scrapes (to $1 \mathrm{~cm}$ depth) were taken for grain size and carbon analysis; the percentages of silt and coarse sand in surface scrapes were calculated following manual sieving over 65 and $500 \mu \mathrm{m}$ mesh, and the percentage organic matter content was determined as loss on ignition at $480^{\circ} \mathrm{C}$ for $12 \mathrm{~h}$. Surface temperature (thermometer probe inserted to $1 \mathrm{~cm}$ below sediment surface) was measured at midday on a clear sunny day. Sediments for nutrient analysis were collected in the field and preserved in an ice box before being taken to the laboratory. Lab nutrient extraction was done using potassium chloride flushed with nitrogen gas (2 min) and shaken for $2 \mathrm{~h}$, to ensure maximum extraction. The sample was then centrifuged at a speed of 2000 rotations per minute for $10 \mathrm{~min}$. The extract was decanted and diluted with distilled water and used for the determination of nutrients. Ammonium, nitrate and phosphorus were determined according to Parsons et al. (1984).

\section{Sapling aboveground biomass and leaf growth}

In order to non-destructively monitor the aboveground biomass of planted trees, we developed biomass to tree-size regression equations for each species, using wild trees of representative sizes: 25, 18 and 8 saplings of Avicennia marina, Bruguiera gymnorrhiza and Ceriops tagal, respectively, with stem diameters ranging from 2 to $22 \mathrm{~mm}$, were selected in an area adjacent to the plots. Tree height, from the ground to the point where the top-most set of leaves join the stem (apical bud), and stem diameter at $30 \mathrm{~cm}$ (A. marina), or between the first and second internode (B. gymnorrhiza and C. tagal) from the ground, were recorded using a tape measure and callipers, respectively, and subsequently the saplings were cut at ground level. Given the subsequent disappearance of initial internodes in the 2 species (B. gymnorrhiza and C. tagal), we adjusted the height at which we took stem diameter measurements making it at half the tree height. Saplings were weighed on site and subsequently oven-dried at $80^{\circ} \mathrm{C}$ to a constant weight to determine the fresh weight to dry weight (dw) ratio. An equation of the form $y=a b^{x}$ was developed using the best predictor available to allow estimation of sapling biomass for planted trees of each species (see Table 1).

We used the developed equations to measure the aboveground biomass in the plots for a period of $4 \mathrm{yr}$, beginning in August 2005. Eighteen plants were randomly selected in each plot. In plots with 2 or 3 species, stratified random sampling was used to give 9 or 6 plants per species, respectively. Tree heights and stem diameters were measured as described above. The total number of leaves and the percentage yellow leaves (a sign of stress) on each of the selected plants were counted, and 10 leaves were further selected at random for measurement of leaf length and maximum width.

The leaf area index in each plot was calculated for each species in turn by multiplying the mean total number of leaves per tree by the mean area per leaf, and by the number of surviving trees per plot, then dividing by the plot area $\left(36 \mathrm{~m}^{2}\right)$. The mean area per leaf was derived from the 10 leaf length-width measurements per tree (conversions of length-width measures into true leaf area was obtained from regression equations based on $>30$ 'wild' leaves).

\section{Statistical analysis}

Data were checked for normality and homogeneity of variances, and transformed where necessary. To ascertain whether the equations were speciesspecific or general, the allometric regression slopes (for relationships between aboveground biomass and stem diameter) for the 3 species were compared using the homogeneity of slopes model test. Effects of year, blocks and treatments on aboveground biomass, tree height, percentage of yellow leaves and leaf area index were analysed using repeated measures analysis of variance $(A N O V A)$; when significant year $\times$ treatment interactions were found, yearly samples were separated and re-analysed using mixed-model 2factor ANOVAs. Year and block were treated as random factors and species treatments as fixed factors.

The 2007, 2008 and 2009 data were explored to ascertain whether significant species richness effects were due to 'the selection effect' or 'the complementarity effect' following the methods of Loreau \& 
Hector (2001) and Fargione et al. (2007). The net effect was calculated as $\Sigma \mathrm{B}-\overline{\mathrm{E}}$, where $\mathrm{B}$ is the total biomass for each species in a plot; $\Sigma \mathrm{B}$ is the biomass of all species in a plot, and $\overline{\mathrm{E}}$ is the average monoculture biomass of all species in that plot. The net effect was partitioned into 2 additive components: the selection effect and the complementarity effect. Selection was calculated as D $\times$ COVARIANCE $(E$, $\triangle \mathrm{RB}$ ), where $\mathrm{D}$ is diversity (i.e. species number), $\mathrm{E}$ represents a species' average monoculture biomass, and $\triangle \mathrm{RB}$ is the difference between the observed relative biomass $(\mathrm{B} / \mathrm{E})$ and the expected relative biomass (1/D). Complementarity was calculated as $\overline{\mathrm{E}} \times$ $\mathrm{D} \times \overline{\Delta \mathrm{RB}}$, where $\overline{\Delta \mathrm{RB}}$ is the average $\Delta \mathrm{RB}$ of all species in a plot. One-sample $t$-tests were used to assess whether the net and the disaggregated species richness effects differed significantly from 0 .

The relationships between initial environmental variables in plots (treated here as predictor variables) and aboveground biomass in the years 2007, 2008 and 2009 were analysed using stepwise multiple regressions (with inclusion of dummy variables in the multiple regression), with alpha values for predictor entry set at 0.2 . Forward and backward selection procedures were compared, and the best model was selected on the basis of the adjusted R square, Mallows' $\mathrm{Cp}$ (used to assess the fitness of regression models) and variance inflation factors (VIF; an index that measures how much of an estimated regression coefficient is increased because of collinearity) as diagnostics. All analyses were performed using SAS ${ }^{\circledR}$ (SAS Institute; used for selection R squared method) and Minitab ${ }^{\circledR}$ software.

\section{RESULTS}

\section{Biomass estimation}

Stem diameter was the best predictor of sapling biomass for each of the 3 species, with $\mathrm{r}^{2}$ values exceeding 0.64 in each case (Table 1 ). We found a significant influence of species $(F=46 . \mathrm{p}=0.048, \mathrm{n}=51)$, and therefore we used different equations to estimate aboveground biomass for each of the 3 species.

\section{Trends in sapling aboveground biomass and other growth parameters}

Aboveground biomass values varied between years (df $=4, F=23.140 \mathrm{p}<0.001$; Fig. 2a). However, growth in the first $2 \mathrm{yr}$ was slow, with significant dif-
Table 1. Avicennia marina, Bruguiera gymnorrhiza and Ceriops tagal. Regressions used to predict total aboveground biomass of individual mangrove saplings from stem diameter. These equations are applicable to a stem diameter range of up to $22 \mathrm{~mm}$. Stem diameter was measured at $30 \mathrm{~cm}$ above the ground in A. marina and between the first 2 internodes in B. gymnorrhiza and C. tagal

\begin{tabular}{|llrrr|}
\hline Species & Equation & $\mathrm{r}^{2}$ & $\mathrm{p}$ & $\mathrm{n}$ \\
\hline A. marina & $0.6896 \times$ stem diameter $^{2.0095}$ & 0.93 & $<0.001$ & 25 \\
B. gymnorrhiza & $0.6494 \times$ stem diameter $^{1.7132}$ & 0.64 & 0.002 & 18 \\
C. tagal & $0.4112 \times$ stem diameter $^{2.1032}$ & 0.94 & $<0.001$ & 8 \\
\hline
\end{tabular}

ferences in species richness only emerging from the third year (2007). In 2005, the mean $( \pm$ SE) aboveground biomass per plot was $3.52 \pm 0.2 \mathrm{~kg} \mathrm{dw}$, while in 2009, the aboveground mean value was $18.90 \pm$ $15.4 \mathrm{~kg}$ dw. Plots containing Avicennia marina had the highest biomass increment over the $5 \mathrm{yr}$, while plots containing a mixture of Bruguiera gymnorrhiza and Ceriops tagal had the lowest aboveground biomass increment values in the same time period (Fig. 2a). Given the significant year $\times$ treatment interaction ( $\mathrm{df}=24, F=2.527, \mathrm{p}<0.001)$, we analysed biomass data for each year separately using 2-way ANOVAs. Treatment effects were observed $2 \mathrm{yr}$ (2007) after planting.

Sapling heights showed a similar pattern, with a significant year effect $(\mathrm{df}=4, F=97.516, \mathrm{p}<0.001$; Fig. 2c), with the mean tree height per plot doubling from $39.6 \pm 0.87 \mathrm{~cm}$ in 2005 to $98.12 \pm 28.10 \mathrm{~cm}$ in 2009. There was a significant year $\times$ treatment interaction $(\mathrm{df}=24, F=1.694, \mathrm{p}=0041)$.

We found a significant year effect on the mean leaf area index $(\mathrm{df}=3, F=17.881, \mathrm{p}<0.001$; Fig. 2b). Mean plot leaf area index in 2005 was $0.003 \pm 0.0005$ and had increased to $0.37 \pm 0.18$ by 2008. Again Avicennia marina exerted a strong influence, with plots containing A. marina having a comparatively higher leaf area index (Fig. 2b). However, there was no significant year $x$ treatment interaction $(\mathrm{df}=3, F=0.034, \mathrm{p}>0.05)$. In contrast with biomass and height, there were significant differences in the leaf area indices of treatments within all 3 years. This may reflect the faster growth of leaves compared with overall biomass, which took longer to accumulate. Significant differences were evident between years in the frequency of yellow leaves ( $\mathrm{df}=4, F=12.258, \mathrm{p}<$ 0.001; Fig. 2d). The highest frequency of yellow leaves was recorded in 2005 at $7.3 \pm 3.7 \%$; this fell in the subsequent years to an average of $1.8 \pm$ $1.4 \%$ by 2008 . 

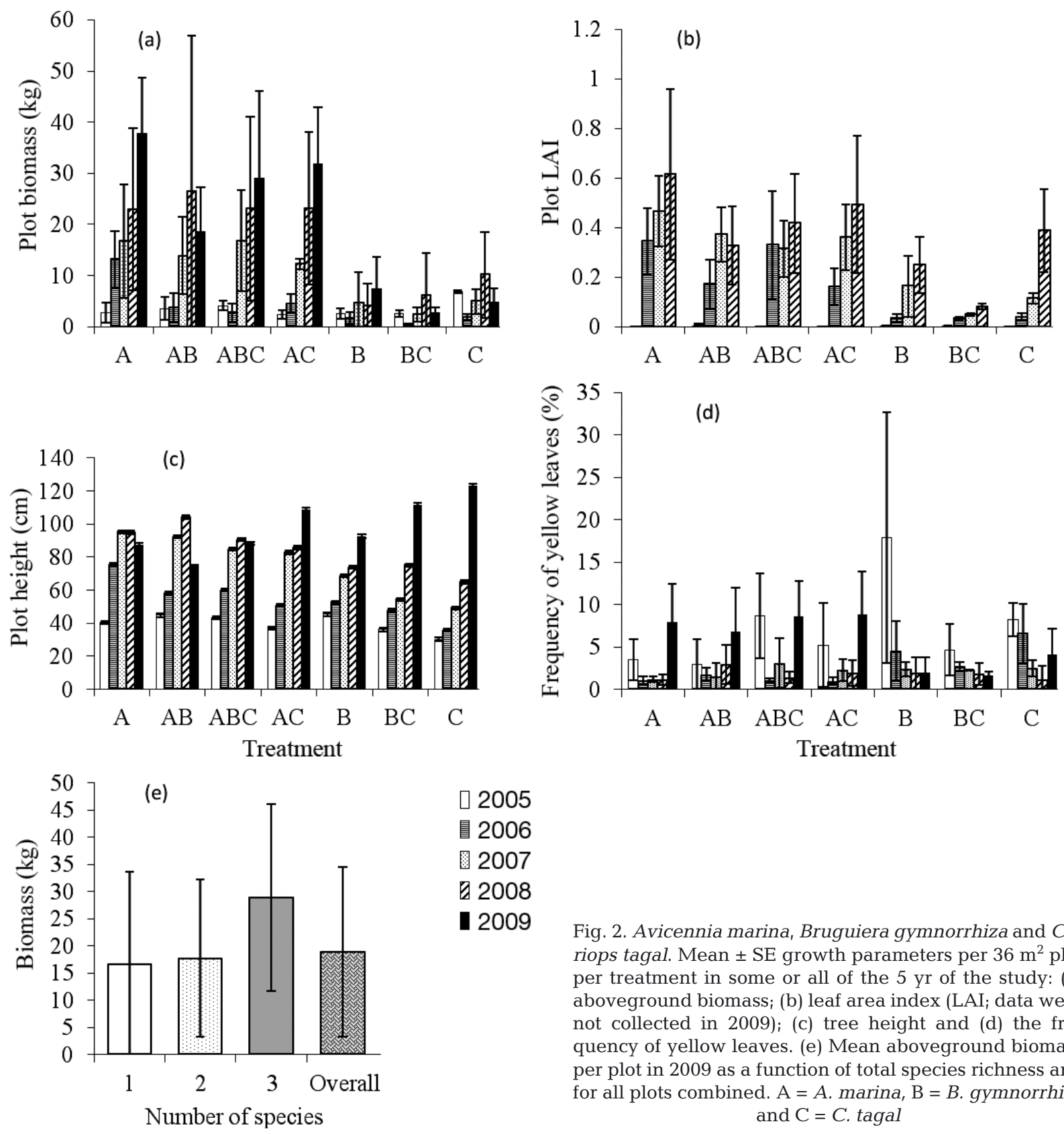

Fig. 2. Avicennia marina, Bruguiera gymnorrhiza and Ceriops tagal. Mean $\pm \mathrm{SE}$ growth parameters per $36 \mathrm{~m}^{2}$ plot per treatment in some or all of the $5 \mathrm{yr}$ of the study: (a) aboveground biomass; (b) leaf area index (LAI; data were not collected in 2009); (c) tree height and (d) the frequency of yellow leaves. (e) Mean aboveground biomass per plot in 2009 as a function of total species richness and for all plots combined. $\mathrm{A}=\mathrm{A}$. marina, $\mathrm{B}=$ B. gymnorrhiza and $\mathrm{C}=\mathrm{C}$. tagal

\section{Aboveground biomass in 2009}

There was a significant treatment effect ( $\mathrm{df}=6, F=$ 23.51, p < 0.05), but no block effect on aboveground biomass in 2009 (Table 2). Post hoc analysis (Tukey test) revealed treatments without Avicennia marina had significantly lower aboveground biomass values compared to other treatments that included A. marina; the mean aboveground biomass per plot with $A$. marina was $29.3 \pm 3.7 \mathrm{~kg} \mathrm{dw}$ compared to $5.0 \pm 2.6 \mathrm{~kg}$ $\mathrm{dw}$ in plots without $A$. marina. The highest mean aboveground biomass, $37.75 \pm 10.86 \mathrm{~kg}$, was recorded in the A. marina monospecific treatment and the lowest, $2.79 \pm 0.97 \mathrm{~kg}$, was recorded in the treatment containing mixed-species plots of Bruguiera gymnorrhiza and Ceriops tagal.

To explore the relative contributions of different species to the total plot dry weights, the mean dry weight per tree was calculated for each species, for each treatment in which it was grown. The average biomass of Avicennia marina individuals was highest in the 3-species treatment and lowest in the mono- 
Table 2. Analysis of variance table showing significance of the mean aboveground biomass (kg dry weight per $36 \mathrm{~m}^{2}$ plot) in blocks and between treatments in 2009

\begin{tabular}{|lrccrl|}
\hline Source & df & SS & MS & $F$ & $p$ \\
\hline Block & 1 & 0.15 & 0.15 & 4.12 & 0.09 \\
Treatment & 6 & 5.00 & 0.83 & 23.51 & 0.001 \\
Interaction & 6 & 0.21 & 0.04 & 0.74 & 0.63 \\
Error & 14 & 0.67 & 0.05 & & \\
\hline
\end{tabular}

specific treatment (Fig. 3), with the difference approaching significance ( $p=0.058)$. However, aboveground biomass in Bruguiera gymnorrhiza and Ceriops tagal did not differ significantly between treatments.

The net effect of species richness showed a positive trend which was particularly marked in the 3-species treatment (Fig. 4c). Of the net effect in this treatment, $85 \%$ was contributed by complementarity in 2007 but this reduced to only $40 \%$ in 2008 (Fig. 4a,b). However, none of the net or disaggregated species richness effects showed significant differences from 0 .

\section{Environmental variables}

Twelve environmental variables (detailed by Kirui et al. 2008) were examined for significant relationships with plot dry weights in 2007, 2008 and 2009. These included the initial environmental factors and a dummy (categorical) variable, Avicennia marina (presence or absence). A. marina was included because of its obvious effects in the other analyses (which were not observed with the other 2 species);

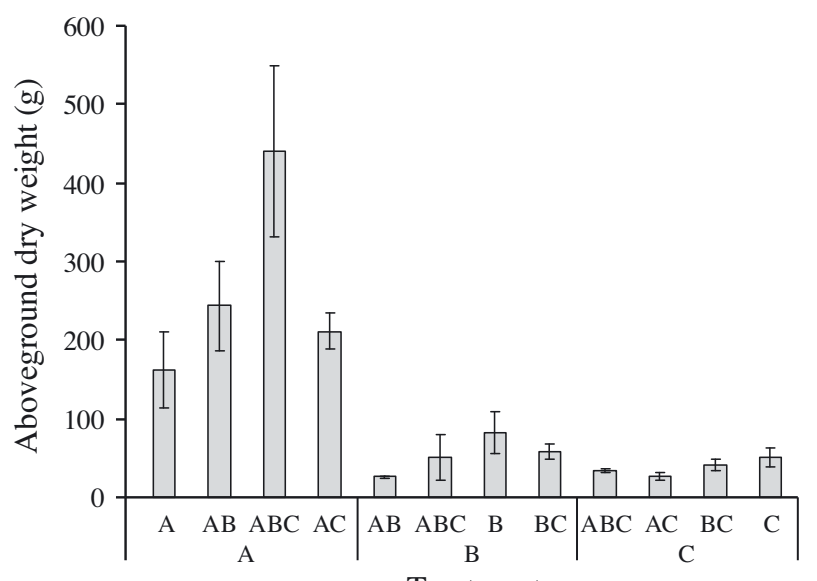

Treatment

Fig. 3. Avicennia marina, Bruguiera gymnorrhiza and Ceriops tagal. Mean $\pm \mathrm{SE}$ aboveground dry weights per tree of each species in different species mixtures. $\mathrm{A}=A$. marina, $\mathrm{B}=$ B. gymnorrhiza and $\mathrm{C}=C$. tagal
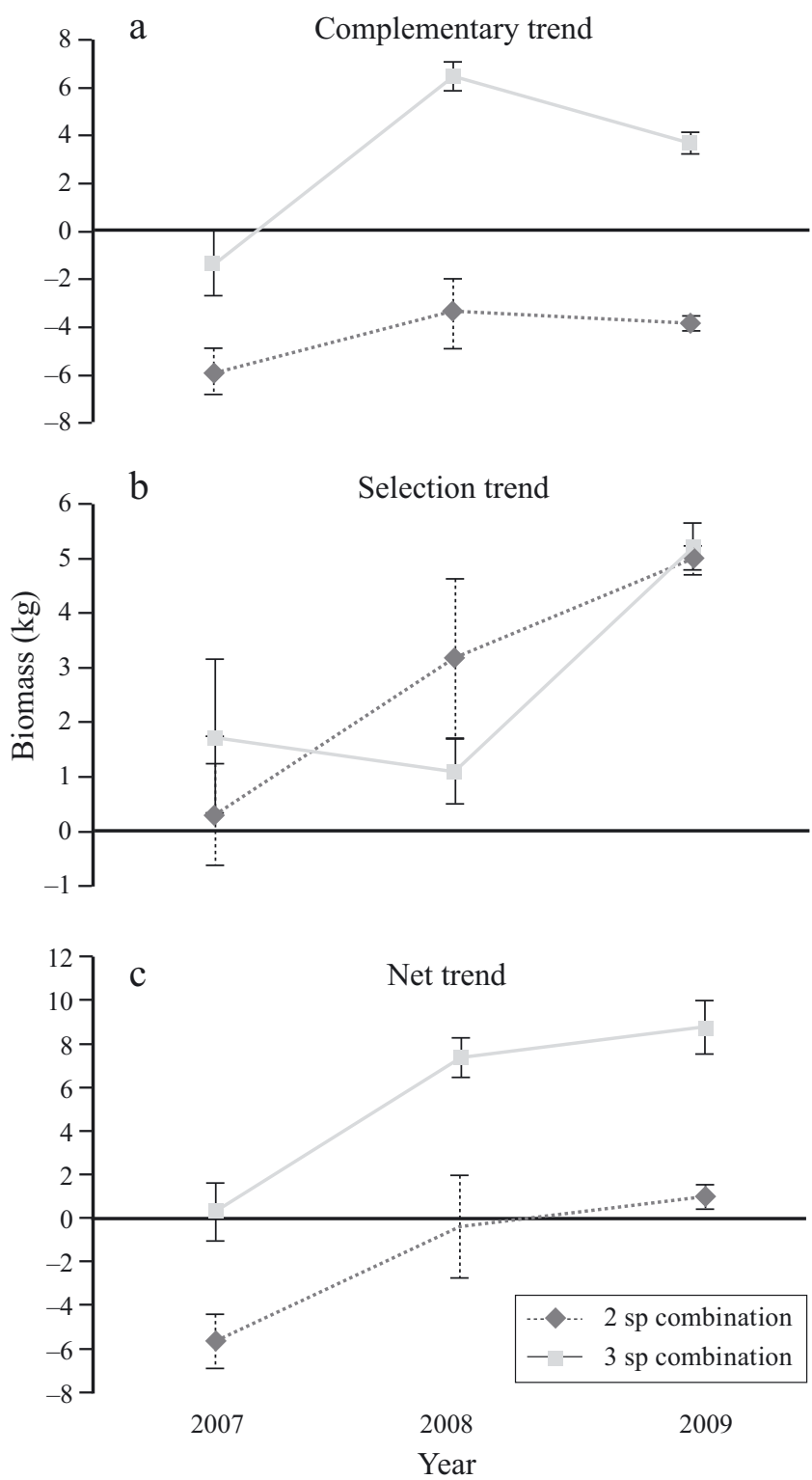

Fig. 4. Avicennia marina, Bruguiera gymnorrhiza and Ceriops tagal. Trends in complementary, selection and net species richness effects $( \pm \mathrm{SE})$ as functions of species number in the plots

hence we intended to examine the importance of initial environmental variables separate from the influence of this factor. Based on $\mathrm{r}^{2}$, VIF and Mallows' $\mathrm{Cp}$ diagnostics, the best model in the year 2007 included A. marina, plot height above datum, sediment salinity and nutrient concentrations (ammonium and phosphates; Table 3). In the years 2008 and 2009, the best model included $A$. marina and sediment salinity (Table 3):

$$
\begin{gathered}
\text { Aboveground dry weight }(\mathrm{g})= \\
44141+29733(\text { A. marina })-763 \text { (salinity) }
\end{gathered}
$$


Table 3. Results for multiple regressions showing coefficients for significant initial environmental variables on aboveground biomass in 2007, 2008 and 2009

\begin{tabular}{|clccc|}
\hline Year & Variable & Coefficient & $T$ & $\mathrm{p}$ \\
\hline 2009 & Intercept & 10266 & 0.50 & 0.623 \\
& Salinity & -762.6 & -3.02. & 0.007 \\
& Avicennia marina & 29733 & 6.99 & 0.000 \\
2008 & Intercept & 36810 & 2.31 & 0.032 \\
& Salinity & -628.7 & -2.06 & 0.053 \\
A. marina & 21129 & 5129 & 0.001 \\
2007 & Intercept & 1.00 & 0.56 & 0.58 \\
Salinity & -0.012 & -3.46 & 0.002 \\
Ammonium & -0.46 & -2.80 & 0.011 \\
Phosphate & -0.17 & -2.44 & 0.023 \\
A. marina & 0.61 & 9.34 & 0.000 \\
Plot heights above datum & 0.01 & 3.73 & 0.001 \\
\hline
\end{tabular}

Hence we observed consistent and strong positive relationships between aboveground biomass and Avicennia marina and enduring negative relationships between aboveground biomass and sediment salinity (Table 3). Salinity at $10 \mathrm{~cm}$ depth varied between 37 and 75, with an average of 54 .

\section{DISCUSSION AND CONCLUSIONS}

We found significant experimental treatment effects on aboveground biomass, mean tree height and leaf area index 5 yr after establishment, driven in particular by the presence or absence of Avicennia marina in a plot (Fig. 2, Table 2). Surprisingly, these effects did not manifest as significant net or dis-aggregated species richness effects (Fig. 4), perhaps because of the relatively low power of the 1 -sample $t$-tests used here. By 2009, the 'selection effect' of the inclusion of the most vigorous species at our site, A. marina, was the dominant contributor to the trends in the net species richness effect observed, consistent with the significant results from the ANOVAs. Such an effect was inferred in earlier studies on a variety of marine ecosystems (Emmerson \& Huxham 2002, Callaway et al. 2003, Bruno et al. 2005) and was invoked as a mechanism linking biodiversity and ecosystem function through the species selection effect in experiments on grassland ecosystems in earlier studies (Tilman \& Downing 1994, Tilman et al. 2001, 2006).

Plots with Avicennia marina tended to show the fastest growth rates, the highest mean heights, the greatest leaf area indices and the lowest percentage of yellow leaves. The relative success of A. marina reflects its inherent tolerance to the high salinity and aridity levels exhibited at the experimental site (Kirui et al. 2008). Removal of the initial forest cover at the field site had led to salinisation of the sediment and a total lack of natural regeneration; under these conditions, it was necessary to plant nursery-reared trees to initiate restoration, and our results suggest that A. marina acts as a 'superplant' (Zedler et al. 2001) in fostering ecosystem recovery. These results are consistent with studies on mangrove saplings which have reported Avicennia possessing pioneer traits especially with respect to aboveground development and the facilitation of wildling (saplings external to the plot) recruitment (McKee 1995, Huxham et al. 2010, Friess et al. 2012) and with work in some terrestrial grassland (Hooper \& Dukes 2004, Hooper et al. 2005), freshwater plant, microbial (Downing 2005, Bruno et al. 2006) and salt marsh communities (Callaway et al. 2003) that showed that productivity was driven by a species identity effect.

In biodiversity-productivity experiments, a positive relationship between monoculture biomass and the relative yield of a species in mixture is predicted to result in 'positive selection' caused by a sampling effect (Fargione et al. 2007); such a relationship is evident in our study, with Avicennia marina not performing well in monoculture and acting as a competitive dominant in polyculture. However, a metaanalysis by Cardinale et al. (2007) and work by Fargione et al. (2007) showed that positive selection effects predominated early during their 10 yr grassland experiment, with the effects of complementarity between species increasing over time. Hence complementarity may emerge more strongly at the current site in subsequent years, and may take much longer to emerge in such relatively slow-growing species.

The mean aboveground biomass of individual Avicennia marina trees was highest in plots containing the 3-species combination and lowest in monospecific plots (Fig. 3). These differences probably resulting from the different effects of inter- and intraspecific competition for resources (Lanta \& Leps 2007). In single-species plots, A. marina plants were competing against one another. In 3-species combination plots, the relatively poorer growth rate of the other 2 species resulted in less competition and hence greater individual growth for A. marina. A. marina profited from being grown in mixtures with less competitive species, i.e. intraspecific competition was higher than interspecific competition, which corresponds to the 'competitive reduction principle' of Vandermeer (1989). Importantly, however, there was no evidence for suppression of growth rates of 
Bruguiera gymnorrhiza and Ceriops tagal when grown with $A$. marina. This is reflected in the positive net species richness effects, with mixed plots showing higher than expected biomasses.

In addition to the strong influence of Avicennia marina, initial environmental variables in plots also affected plant growth. There were significant negative correlations with sediment salinity, which reached 77 in 1 plot. Salinity has previously been noted to strongly influence survival of the planted species at the current site (Kirui et al. 2008) and has been widely reported as a factor limiting growth in mangroves (Naidoo 1990, Jayatissa et al. 2008); hence this strong effect is unsurprising. The negative relationships with phosphate and ammonium found in the first year (and which subsequently disappeared) are more difficult to explain but may result from confounding conditions in oxygen-poor, wetter sediment.

In conclusion, aboveground productivity over the $5 \mathrm{yr}$ of our study was driven by the presence of Avicennia marina, which was the competitively dominant species at our site, and which strongly influenced productivity in the plots. This was probably because of its tolerance of salt (which showed a strongly negative association with productivity) and other environmental stressors. At this stage in our experiment there were no apparent productivity benefits from mixing species, although the 3 -species treatment did achieve similar biomass to monospecific A. marina plots (Fig. 3) because of reduced intraspecific competition. This implies that $A$. marina can be used on its own to restore productivity at similar stressed sites, although there may be benefits for other ecosystem functions in mixing species.

Acknowledgements. This work was supported by the Leverhulme Trust, Western Indian Ocean Marine Science and by the Earthwatch Institute. We are grateful to Earthwatch volunteers and S. Laitani for field assistance.

\section{LITERATURE CITED}

Bosire JO, Dahdouh-Guebas F, Kairo JG, Koedam N (2003) Colonization of non-planted mangrove species into restored mangrove stands in Gazi Bay, Kenya. Aquat Bot 76:267-279

Bosire JO, Dahdouh-Guebas F, Walton M, Crona BI and others (2008) Functionality of restored mangroves: a review. Aquat Bot 89:251-259

Bruno JF, Katharyin EB, Duffy JE, Lee SC, Kertesz JS (2005) Effects of macroalgal species identity and richness on primary production in benthic marine communities. Ecol Lett 8:1165-1174

Bruno JF, Lee SC, Kertesz JS, Carpenter RC, Long ZT, Duffy JE (2006) Partitioning the effects of algal species identity and richness on benthic marine primary production. Oikos 115:170-178

Callaway JC, Sullivan G, Zedler JB (2003) Species-rich plantings increase biomass and nitrogen accumulation in a wetland restoration experiment. Ecol Appl 13: 1626-1639

Cardinale BJ, Wright JP, Cadotte MW, Carroll IT and others (2007) Impacts of plant diversity on biomass production increase through time because of species complementarity. Proc Natl Acad Sci USA 104:18123-18128

Cardinale BJ, Matulich KL, Hooper DU, Byrnes JE and others (2011) The functional role of producer diversity in ecosystems. Am J Bot 98:572-592

> Downing AL (2005) Relative effects of species composition and richness on ecosystem properties in ponds. Ecology 86:701-715

Emmerson MC, Huxham M (2002) How can marine ecology contribute to the biodiversity-ecosystem functioning debate? In: Loreau M, Naeem S, Inchausti P (eds) Biodiversity and ecosystem functioning: synthesis and perspectives. Oxford University Press, New York, NY, p 139-146

> Fargione J, Tilman D, Dybzinski R, Lambers JHR and others (2007) From selection to complementarity: shifts in the causes of biodiversity-productivity relationships in a long-term biodiversity experiment. Proc R Soc Lond B Biol Sci 274:871-876

> Field CB, Osborn JG, Hoffmann LL, Polsenberg JF and others (1998) Mangrove biodiversity and ecosystem function. Glob Ecol Biogeogr Lett 7:3-14

Fornara DA, Tilman D (2009) Ecological mechanisms associated with the positive diversity-productivity relationship in an N-limited grassland. Ecology 90:408-418

Friess DA, Krauss KW, Horstman EM, Balke T, Bouma TJ, Galli D, Webb EL (2012) Are all intertidal wetlands naturally created equal? Bottlenecks, thresholds and knowledge gaps to mangrove and saltmarsh ecosystems. Biol Rev Camb Philos Soc 87:346-366

Hector A, Hooper RE (2002) Darwin and the first ecological experiment. Science 295:639-640

> Hector A, Schmid B, Beierkuhnlein C, Caldeira MC and others (1999) Plant diversity and productivity experiments in European grasslands. Science 286:1123-1127

Hector A, Philipson C, Saner P, Chamagne J and others (2011) The Sabah Biodiversity Experiment: a long-term test of the role of tree diversity in restoring tropical forest structure and functioning. Philos Trans R Soc B Biol Sci 366:3303-3315

Hooper DU, Dukes JS (2004) Overyielding among plant functional groups in a long-term experiment. Ecol Lett 7: 95-105

> Hooper DU, Chapin FS, Ewel JJ, Hector A and others (2005) Effects of biodiversity on ecosystem functioning: a consensus of current knowledge. Ecol Monogr 75:3-35

> Huston MA (1997) Hidden treatments in ecological experiments: re-evaluating the ecosystem function of biodiversity. Oecologia 110:449-460

> Huxham M, Kumara M, Jayatissa LP, Krauss KW and others (2010) Intra and inter-specific facilitation in mangroves may increase resilience to climate change threats. Philos Trans R Soc Lond B Biol Sci 365:2127-2135

Isbell FI, Wilsey BJ (2011) Increasing native, but not exotic, biodiversity increases aboveground productivity in ungrazed and intensely grazed grasslands. Oecologia 165: $771-781$ 
Jayatissa LP, Wickramasinghe WAADL, Dahdouh-Guebas F, Huxham M (2008) Interspecific variations in responses of mangrove seedlings to two contrasting salinities. Int Rev Hydrobiol 93:700-710

Kairo JG (1995) Community participatory forestry for rehabilitation of deforested mangrove areas of Gazi bay (Kenya): a first approach. Final technical report. University of Nairobi

Kairo JG, Lang'at JKS, Dahdouh-Guebas F, Bosire J, Karachi M (2008) Structural development and productivity of replanted mangrove plantations in Kenya. For Ecol Manag 255:2670-2677

Kareiva P, Watts S, McDonald R, Boucher T (2007) Domesticated nature: shaping landscapes and ecosystems for human welfare. Science 316:1866-1869

Kirui B, Kairo JG, Karachi M (2006) Allometric equations for estimating above-ground biomass of Rhizophora mucronata Lamk. (Rhizophoraceae) mangroves at Gazi Bay, Kenya. West Indian Ocean J Mar Sci 5:27-34

Kirui BYK, Huxham M, Kairo J, Skov M (2008) Influence of species richness and environmental context on early survival of replanted mangroves at Gazi bay, Kenya. Hydrobiologia 603:171-181

Lanta V, Leps J (2007) Effects of species and functional group richness on production in two fertility environments: an experiment with communities of perennial plants. Acta Oecol 32:93-103

Loreau M, Hector A (2001) Partitioning selection and complementarity in biodiversity experiments. Nature 412: 72-76

MacNae W (1968) A general account of the fauna and flora of mangrove swamps and forests in the Indo-WestPacific region. Adv Mar Biol 6:73-270

McKee KL (1995) Interspecific variation in growth, biomass partitioning, and defensive characteristics of neotropical mangrove seedlings: response to light and nutrient availability. Am J Bot 82:299-307

Mukhopadhyay SK, Biswas H, De TK, Jana TK (2006) Fluxes of nutrients from the tropical River Hooghly at the landocean boundary of Sundarbans, NE Coast of Bay of Bengal, India. J Mar Syst 62:9-21

Naidoo G (1990) Effects of nitrate, ammonium and salinity on the growth of the mangrove Bruguiera gymnorrhiza (L.) Lam. Aquat Bot 38:209-219

Oelmann Y, Potvin C, Mark T, Werther L, Tapernon S,

Editorial responsibility: Just Cebrian,

Dauphin Island, Alabama, USA
Wilcke W (2010) Tree mixture effects on aboveground nutrient pools of trees in an experimental plantation in Panama. Plant Soil 326:199-212

Parsons TR, Takahashi M, Hargrove B (1984) Biological oceanographic processes. Pergamon Press, New York, NY

Reich PB, Tilman D, Isbell F, Mueller K, Hobbie SE, Flynn DFB, Eisenhauer N (2012) Impacts of biodiversity loss escalate through time as redundancy fades. Science 336: 589-592

Schmid B (2002) The species richness-productivity controversy. Trends Ecol Evol 17:113-114

Skov MW, Hartnoll RG (2002) Paradoxical selective feeding on a low-nutrient diet: Why do mangrove crabs eat leaves? Oecologia 131:1-7

Spehn EM, Hector A, Joshi J, Scherer-Lorenzen M and others (2005) Ecosystem effects of biodiversity manipulations in European grasslands. Ecol Monogr 75:37-63

Tack JF, Polk P (1999) Tropical catchments, their interaction with the coastal zone. In: Harper D, Brown T (eds) Sustainable management in tropical catchments. John Wiley and Sons, London, p 359-371

- Tilman D, Downing JA (1994) Biodiversity and stability in grasslands. Nature 367:363-365

Tilman D, Reich PB, Knops J, Wedin D, Mielke T, Lehman C (2001) Diversity and productivity in a long-term grassland experiment. Science 294:843-845

Tilman D, Reich PB, Knops JMH (2006) Biodiversity and ecosystem stability in a decade-long grassland experiment. Nature 441:629-632

Tomlinson CB (1986) The botany of mangroves. Cambridge Tropical Biology Series. Cambridge University Press, Cambridge

Vandermeer JH (1989) The ecology of intercropping. Cambridge University Press, Cambridge

Watson JG (1928) Mangrove forest of Malay Peninsula, Vol 6. Fraser and Neave, Singapore

Zedler JB, Callaway JC, Sullivan G (2001) Declining biodiversity: why species matter and how their functions might be restored in Californian tidal marshes. Bioscience 51:1005-1017

Zeugin F, Potvin C, Jansa J, Scherer-Lorenzen M (2010) Is tree diversity an important driver for phosphorus and nitrogen acquisition of a young tropical plantation? For Ecol Manag 260:1424-1433

Submitted: April 2, 2012; Accepted: August 13, 2012

Proofs received from author(s): September 14, 2012 